\title{
Nephrocutaneous fistula due to renal stone disease presenting as non-healing abdominal wall sinus: lessons from two cases
}

\author{
Sanjay Marwah, Nityasha Daral, Himanshu Sharma, Pooja Sharma, Vikram Pal Singh \\ Department of Surgery, Pt BDS Post graduate Institute of Medical Sciences, Rohtak, Haryana, India.
}

Key words: Stag horn calculi; xanthogranulomatous pyelonephritis; perinephric abscess; non-healing sinus

\section{Introduction}

Stag horn renal calculi usually remain asymptomatic and may lead to xanthogranulomatous pyelonephritis, pyonephrosis and non-functioning kidney in long standing cases. If remained neglected, the inflammatory process may extend beyond kidney leading to perinephric abscess. Rarely, this abscess may rupture through abdominal wall presenting as non-healing sinus in the flank region $[1,2]$. The authors report two such unusual cases that were managed successfully by subcapsular nephrectomy.

\section{Case report - Case 1}

In 2012, a twenty two year old female presented with history of painful swelling in the right lumbar region of four months duration. It was clinically diagnosed as an abscess and was drained under local anesthesia in a private hospital. However, a sinus developed at the drainage site with recurrent discharge of pus that did not heal with antibiotics and regular dressings. The patient complained of off and on fever and pain at the site of sinus. A wedge biopsy from the margin of sinus came out to be non-specific inflammatory lesion. The patient also had a dull aching pain at the site of abscess for the last four years.
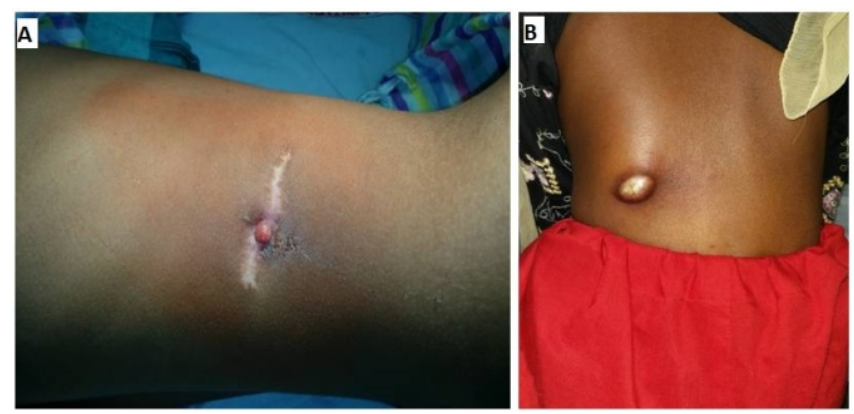

Figure 1A - Clinical photograph showing transverse scar mark with sinus opening in right flank

Fig 1B - Clinical photograph showing swelling left renal area

Correspondence: Sanjay Marwah

E-mail: drsanjay.marwah@gmail.com

Received: 18-01-2017 Accepted: 02-07-2017

(iD) http://orcid.org/0000-0002-0300-2779

DOI: http://doi.org/10.4038/sljs.v35i2.8390

The Sri Lanka Journal of Surgery 2017; 35(2): 32-33
There was no history of tuberculosis, diabetes or any other chronic ailment in the past.On examination there was a small sinus in the center of a transversely placed scar mark of previous incision with pouting granulation tissue located in right flank near the tip of 12th rib (Figure 1A). On investigation, her hemoglobin was $9 \mathrm{~g} / \mathrm{dl}$, white cell count $10.3 \times 106 / L$ with $62 \%$ neutrophils, urine analysis showed 20 24 pus cells/ HPF, urine culture revealed E. Coli sensitive to amikacin, serum creatinine $65 \mathrm{mmol} / \mathrm{L}$. Her x-ray abdomen revealed multiple radio-opaque shadows in the right renal area suggestive of triple phosphate stones. Ultrasound abdomen showed a contracted right kidney with multiple calculi in it along with perinephric collection. Intravenous pyelogram revealed normal functioning left kidney and nonfunctioning right kidney with multiple stones in it. Tc99m-dimercaptosuccinic acid (DMSA) renal scan demonstrated non-functioning right kidney.

The patient underwent right subcapsular nephrectomy through flank incision including excision of sinus tract and previous scar. The kidney was small, contracted with multiple stones in it. There were dense perinephric adhesions and abscess. Post operative recovery was uneventful. The histopathology report of the surgical specimen revealed xanthogranulomatous pyelonephritis.

\section{Case 2}

In 2016, a twenty four year old female presented with a two month history of a painful swelling in the left flank. The patient also complained of dull aching pain at the site of swelling for the last one year. There was no history of fever and her bowel and bladder habits were normal. There was no past history of any medical or surgical illness, including tuberculosis, diabetes or trauma. The physical examination revealed a $5 \times 3 \mathrm{~cm}$ oval swelling in the left flank region on the back with local signs of inflammation (Figure 1B). The swelling ruptured during examination with discharge of thick creamy pus. With our previous experience of a case of nephrocutneous fistula with similar presentation, the same pathology was suspected in this case and urgent ultrasound abdomen was done. It revealed dilated pelvicalyceal system in left kidney with multiple calculi and a hypoechoic collection in inter-muscular plane in the perinephric area that was 



Figure 2 A,B - IVP and CECT abdomen showing non-functioning left kidney with multiple radio-opaque shadows Figure 2 C - Nephrectomy specimen with multiple stag horn calculi

communicating to the skin surface.

Her urine and hematological investigations were normal. Her intravenous pyelogram revealed non-functioning left kidney with multiple stones (Fig 2A). CECT abdomen demonstrated non-functioning kidney with pyonephrosis and stag horn calculi along with perinephric paravertebral collection (Figure 2B). The left kidney was non-functioning on DMSA renal scan. The patient underwent subcapsular nephrectomy and excision of the fistulous tract through a left flank incision. Dense adhesions of the kidney to the psoas muscle and posterior peritoneum were carefully dissected taking care to protect descending colon. The kidney was pyonephrotic with multiple calculi in it (Figure 2C). The postoperative period was uneventful and the patient was discharged on the seventh day. The pathological examination of the surgical specimen revealed chronic pyelonephritis.

\section{Discussion}

Triple phosphate or stag horn stones are well known for remaining asymptomatic for a prolonged time and may lead to silent damage to the affected kidney. The obstruction and infection of urinary system caused by staghorn calculi might rarely lead to pyonephrosis and xanthogranulomatous pyelonephritis (XGP). In neglected and untreated cases, infection may extend to involve Gerota's fascia, perinephric fat and sometimes may rupture through overlying skin in the flank region as happened in both of our cases [2]. Both of our patients were poor, uneducated labourers with rural background and might have neglected the mild symptoms of renal stone disease leading to this complication.

Apart from causing cutaneous fistula, XGP of the affected kidney is sometimes known to involve overlying colon, thoracic cavity upwards ( nephrobronchial fistula) or even unusual involvement of knee has been reported [2 - 4]. Rarely, XGP may present with spontaneous expulsion of renal calculi through nephrocutaneous fistula track [4]. In differential diagnosis, underlying renal tuberculosis and renal cell carcinoma needs to be excluded [1]. CECT abdomen is the investigation of choice that delineates the lesion with underlying stones as well as demonstrates non-functioning kidney. The recommended treatment is subcapsular nephrectomy with excision of sinus tract as was done in both of our cases. Hand-assisted laparoscopic nephrectomy after failed flank exploration has also been reported in such cases [5].

\section{References}

1. Ansari MS, Singh I, Dogra PN. Spontaneous nephrocutaneous fistula-2 unusual case reports with review of literature. Int Urol Nephrol. 2004; 36 (2) : 239 - 43. PMID: 15368703

2. Snoj Z, Savic N, Regvat J. Late complication of a renal calculus: fistulisation to the psoas muscle, skin and bronchi. Int Braz J Urol. 2015; 41(4): 808-812. http://doi.org/10.1590/S1677-5538.IBJU.2014.0541.

3. Puthenveetil RT, Baishya D, Barua S, Sarma D. Unusual case of nephrocutaneous fistula - Our experience. Asian J Urol 2016;3: 56e58 http://dx.doi.org/10.1016/j.ajur.2015.10.005.

4. Iseki T, Kawamura M. Spontaneous passage of renal calculi through nephrocutaneous fistula due to calculous pyelonephritis. Br J Urol. 1987 Mar;59(3):285-6 PMID:3567499

5. Doddamani D, Hemal AK, Ansari MS. Ureteral stent - help or hindrance? In healing of post traumatic nephro-cutaneous fistula. Int Urol Nephrol. 2001; 33: 621-3 PMID:12452612.

\section{Key Points:}

- Nephrocutaneous fistula is a rare clinical entity that may present as non-healing sinus in flank region.

- It usually presents as a delayed complication of staghorn renal calculi.

- It is best diagnosed with CECT abdomen and subcapsular nephrectomy is the treatment of choice. 